\title{
The reaction of 1-ethylthio-3-iminopyrrolizines with hydroxylamine. A new synthesis of 3-aminoisoxazoles
}

\author{
Lyubov' N. Sobenina, Vladislav N. Drichkov, Al'bina I. Mikhaleva, Ol'ga V. Petrova, Igor' \\ A. Ushakov, and Boris A. Trofimov \\ A. E. Favorsky Irkutsk Institute of Chemistry Siberian Branch of the Russian Academy of \\ Sciences 1 Favorsky Str., Irkutsk 664033, Russia \\ E-mail: sobenina@irioch.irk.ru
}

\section{Dedicated to Prof. Vladimir Minkin on the occasion of his $\mathbf{7 0}^{\text {th }}$ birthday}

(received 09 Nov 04; accepted 06 Jan 05; published on the web 22 Jan 05)

\begin{abstract}
The reaction of 1-ethylthio-3-iminopyrrolizine-2-carbonitriles with hydroxylamine leads to 1hydroxylamino-3-iminopyrrolizine-2-carbonitriles, whereas 1-ethylthio-3-iminopyrrolizine-2carboxamides and hydroxylamines give 3-aminoisoxazoles, as major products. The exchange of the ethylthio group for the hydroxylamine moiety is a side reaction of this approach.
\end{abstract}

Keywords: 1-Ethylthio-3-iminopyrrolizine-2-carbonitriles, 1-ethylthio-3-iminopyrrolizine-2carboxamides, hydroxylamine, 3-aminoisoxazoles, exchange

\section{Introduction}

The pyrrolizine and indolizine alkaloids constitute a very large family of natural products having a wide range of biological activities and are isolated from a wide variety of plants, insects, animals, marine organisms and microbes. ${ }^{1}$ Derivatives of pyrrolizines are used for antiinflammation and analgesia, ${ }^{2}$ as aromatase ${ }^{3}$ and tumor ${ }^{4}$ inhibitors. In view of the intense interest in these compounds and the scarcity of natural samples, a number of new methodologies and strategies have been developed towards their synthesis. ${ }^{5-8}$ We have recently reported that 1ethylthio-3-iminopyrrolizines, the products of intramolecular cyclization of 2-(1-ethylthio-2cyanoethenyl)pyrroles, ${ }^{9}$ when treated with secondary amines in methanol, readily exchange their ethylthio group for the amine moiety, thus forming the corresponding 1 -aminopyrrolizines. ${ }^{10}$ In the presence of water, the direction of the reaction of 1-ethylthio-3-iminopyrrolizines with secondary amines is determined by the nature of the substituents in the pyrrolizine cycle: pyrrolizine-2-carbonitriles exchange its ethylthio group for an amine residue only, whereas pyrrolizine-2-carboxamides undergo ring-opening to give the corresponding 2-(1-amino-2- 
carbamoyl-2-cyanoethenyl)pyrroles. ${ }^{11}$ With hydrazine hydrate as the amine component, both pyrrolizine-2-carbonitriles and pyrrolizine-2-carboxamides give 1-hydrazino-3iminopyrrolyzines in high yields. ${ }^{12}$ With the goal of further studying the reaction of 1ethylthiopyrrolizines with amines and establishing its scope and selectivity, as well as for the synthesis of new functionallized aminopyrrolizines with nitrile and carbamide substituents available for further modifications, we have investigated the interaction of 1-ethylthio-3iminopyrrolizines 1a,b and 1c-e with hydroxylamine.

\section{Results and Discussion}

As found, 1-ethylthio-3-iminopyrrolizines 1a,b upon heating $\left(40-45^{\circ} \mathrm{C}, 30 \mathrm{~min}\right)$ in methanol with aqueous hydroxylamine readily exchanges the ethylthio group for the hydroxylamino moiety to form 1-hydroxylamino-3-iminopyrrolizines $\mathbf{2 a , b}$ in 35 and $41 \%$ yield, respectively (Scheme 1). The low yield can probably be explained by the formation of oligomers during the reaction.
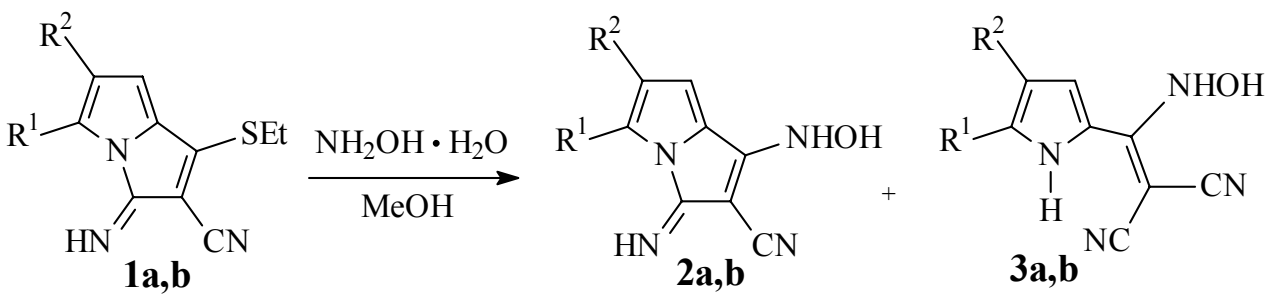

\begin{tabular}{cccc}
\hline Compound & $\mathrm{R}^{1}$ & $\mathrm{R}^{2}$ & $\begin{array}{c}\text { Yield } \\
\mathbf{2 a}, \mathbf{b}, \%\end{array}$ \\
\hline $\mathbf{1 a - 3 a}$ & $n$-Pr & $\mathrm{Et}$ & 35 \\
$\mathbf{1 b - 3 b}$ & $\left(\mathrm{CH}_{2}\right)_{4}$ & 41 \\
\hline
\end{tabular}

\section{Scheme 1}

The reaction was found to be chemoselective: other products were not detected in the reaction mixture (the reaction was monitored by TLC).

However, 1-hydroxylamino-3-iminopyrrolizines 2a,b are unstable in DMSO solutions and transform to 2-(2,2-dicyano-1-hydroxylaminoethenyl)pyrroles $\mathbf{3 a , b}$, the concentration of which reaches $12 \%$ after $1 \mathrm{~h}\left({ }^{1} \mathrm{H} \mathrm{NMR}\right)$. However, it was impossible to reach completion of this transformation.

Under analogous conditions, with 1-ethyl-3-iminopyrrolizin-2-carboxamides 1c-e the reaction chemoselectivity breaches and 3-aminoisoxazoles 4c-e, as major products, are formed unexpectedly because of a different stability of the compounds in methanol compared to the nitrile analogues. The exchange of the ethylthio group for hydroxylamine in 3-iminopyrrolizines 
1c-e, bearing a carbamoyl group, to form 1-hydroxylamino-3-iminopyrrolizines $\mathbf{5 c - e}$ is a side reaction of this approach. The ratio of products $4 \mathbf{c}-\mathbf{e}: \mathbf{5 c - e}$ is $\sim 2.5: 1$. 3-Aminoisoxazoles $4 \mathbf{c}-\mathbf{e}$ were isolated by column chromatography $\left(\mathrm{Al}_{2} \mathrm{O}_{3}\right.$, eluent: methanol), while 1-hydroxylamino-3iminopyrrolizines $\mathbf{5 c - e}$ could not be isolated and were characterized by their ${ }^{1} \mathrm{H}$ NMR spectra in the reaction mixtures.
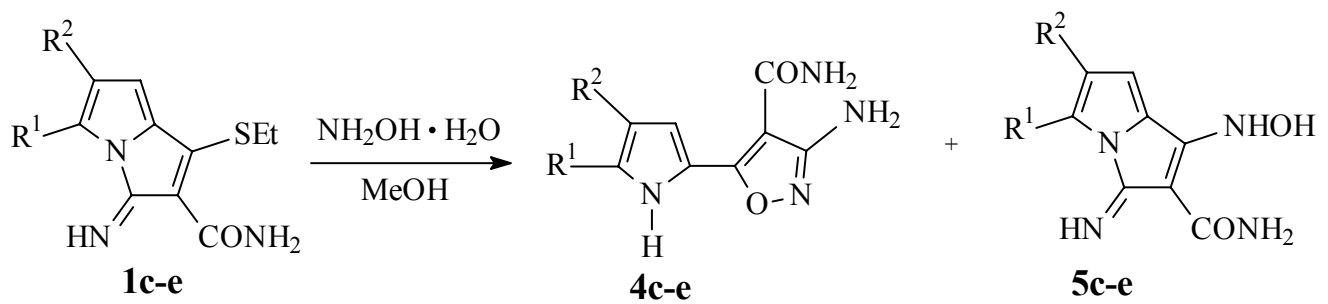

\begin{tabular}{cccc}
\hline Compound & $\mathrm{R}^{1}$ & $\mathrm{R}^{2}$ & Yield 4c-e, \% \\
\hline $\mathbf{1 c - 5 c}$ & $n-\mathrm{Pr}$ & Et & 49 \\
$\mathbf{1 d - 5 d}$ & $n$ - $\mathrm{Bu}$ & $n$-Pr & 33 \\
$\mathbf{1 e - 5 e}$ & \multicolumn{2}{c}{$\left(\mathrm{CH}_{2}\right)_{4}$} & 40 \\
\hline
\end{tabular}

\section{Scheme 2}

The formation of 3-aminoisoxazoles is likely to be the result of the ring opening of the pyrrolizines 5c-e and formation of the pyrroles 6c-e with the syn-disposition of the nitrile function relative to the $\mathrm{NH}$ group of the pyrrole ring. Thus, pyrroles $\mathbf{6 c}-\mathbf{e}$ add a second molecule of hydroxylamine at the nitrile group and the adducts $\mathbf{7 c - e}$ ring close to eliminate hydroxylamine giving the major products 3-aminoisoxazoles 4c-e (Scheme 3).<smiles>[R]c1cc2n(c1[R])C(=N)C(C(N)=O)=C2NO</smiles>

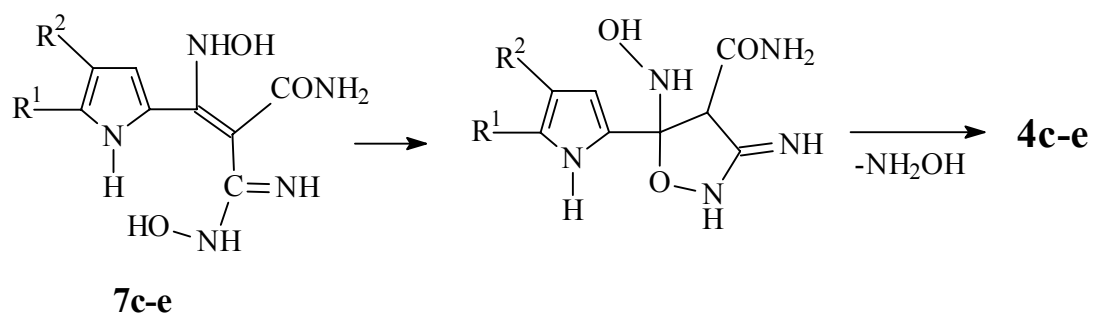

\section{Scheme 3}


Reacting the pyrrolizine $1 \mathrm{e}$ with hydroxylamine in $n$-propanol $\left(85^{\circ} \mathrm{C}, 10 \mathrm{~min}\right)$ leads to the isolation of 3-aminoisoxazole $4 \mathbf{e}$ from the reaction mixture in pure form (as precipitates).

1-Hydroxylamino-3-iminopyrrolizines $\mathbf{2 a , b}$ are orange solids, 3-aminoisoxazoles $\mathbf{4 c - e}$ are creamcoloured lustrous crystals.

According to elemental analyses, 1-hydroxylamino-3-iminopyrrolizine $\mathbf{2 b}$ incorporates a molecule of acetone, which is also confirmed by ${ }^{1} \mathrm{H}$ NMR.

In the ${ }^{1} \mathrm{H}$ NMR spectra of 1-hydroxylamino-3-iminopyrrolizines $\mathbf{2 a , b} \mathrm{H}-3$ pyrrole hydrogen appears as a singlet at 6.33-6.45 ppm, the hydroxyl hydrogen signals are in the 10.88-11.00 ppm region. The $\mathrm{NH}$ hydrogens resonate at 7.77-7.84 ppm.

Structures of 3-aminoisoxazoles $4 \mathbf{c}$-e were reliably confirmed by a series of ${ }^{1} \mathrm{H}$ and ${ }^{13} \mathrm{C} N M R$ experiments including homo- (NOESY, COSY) and heteronuclear (HMBC and HSQC) 2D correlations. Additionally, using the 2D HSQC technique optimized for the value of the direct ${ }^{1} J(\mathrm{H}, \mathrm{N})$ coupling constant, which equals $90 \mathrm{~Hz},{ }^{15} \mathrm{~N}$ chemical shifts for nitrogen atoms in 3amino groups were obtained. They are in agreement with the known values. ${ }^{13}$

The ${ }^{1} \mathrm{H}$ NMR spectra of 3 -aminoisoxazoles $4 \mathbf{c}$-e show peaks of the pyrrole ring hydrogens (H-3) as a doublet as well as broadened peaks of NH hydrogens of pyrrole, amino and carbamoyl moieties. The amino group hydrogens in 3-aminoisoxazoles 4c-e resonate at 6.92-7.53 ppm.

In the $2 \mathrm{D} \mathrm{HMBC}$ spectrum of 3-aminoisoxazole $4 \mathbf{e}$, the hydrogens of 3-amino group, representing a narrow singlet in ${ }^{1} \mathrm{H}$ NMR spectrum (in DMSO), show cross-peaks with the ${ }^{13} \mathrm{C}$ signals at $162.1 \mathrm{ppm}$ (isoxazole $\mathrm{C}-3$ ) and $98.52 \mathrm{ppm}$ (isoxazole $\mathrm{C}-4$ ). The peak of $\mathrm{H}-3$ in the pyrrole ring has cross-peaks with the ${ }^{13} \mathrm{C}$ resonances of quaternary carbon atoms in the pyrrole ring and the signal at $162.95 \mathrm{ppm}$, assigned to $\mathrm{C}-5$ in isoxazole.

Analysis of 2D NOESY spectra allows to determine exactly the position of $\mathrm{CONH}_{2}$ group as C-4. This group shows a NOE effect with the H-3 hydrogen and the 3-amino group.

Physical constants and spectral characteristics of all compounds synthesized are given in the Experimental section.

Analogously, one could think about a further reaction of compounds 3a,b with hydroxylamine. However, the compounds 3a,b can be transformed into 5-amino-3-(pyrrole-2yl)isoxazole without treatment with hydroxylamine. 2-(1H-Pyrrol-2-yl)(hydroxyimino)-methylN'1,N'3-dihydroxypropanediimidamides are the products of hydroxylamine binding to both nitrile groups. ${ }^{14}$

In summary, the reaction of 1-ethylthio-3-iminopyrrolizine-2-carbonitriles with hydroxylamine leads to 1-hydroxylamino-3-iminopyrrolizine-2-carbonitriles, whereas 1ethylthio-3-iminopyrrolizine-2-carboxamides and hydroxylamines give 3-aminoisoxazoles, as major products. 


\section{Experimental Section}

General Procedures. Melting points are uncorrected. IR spectra (400-4000 $\left.\mathrm{cm}^{-1}\right)$ were recorded in $\mathrm{KBr}$ pellets on a Bruker IFS-25 spectrometer. ${ }^{1} \mathrm{H}$ and ${ }^{13} \mathrm{C}$ NMR spectra were recorded on a Bruker DPX 250 [250.13 $\left({ }^{1} \mathrm{H}\right)$ and $62.9\left({ }^{13} \mathrm{C}\right) \mathrm{MHz}$, respectively] and Bruker DPX 400 [400.13 $\left.\left({ }^{1} \mathrm{H}\right) \mathrm{MHz}\right]$ instruments in DMSO- $d_{6}$ and referenced to internal HMDS. Structure of compounds was established by ${ }^{1} \mathrm{H}$ and ${ }^{13} \mathrm{C}$ NMR data obtained using $2 \mathrm{D}$ NMR techniques. Assignment of ${ }^{13} \mathrm{C}$ resonances was made by employing the $2 \mathrm{D} \mathrm{HSQC}{ }^{15}$ and $\mathrm{HMBC}^{16}$ heteronuclear correlation techniques.

For recording of 2D HMBC spectra, pulse sequence delays optimized for values of the direct ${ }^{1} J(\mathrm{H}, \mathrm{C})=145 \mathrm{~Hz}$ and $\operatorname{far}^{\mathrm{n}} J(\mathrm{H}, \mathrm{C})=5 \mathrm{~Hz}$ coupling constants were used.

Analysis of reaction mixtures and purity control of compounds obtained were performed by TLC on Silufol UV-254 plates, eluent: diethyl ether - ethanol, 10 : 1. 3-Aminoisoxazoles were recrystallized from a $1: 1$ acetone-water mixture.

The starting 1-ethylthio-3-iminopyrrolizines were synthesized according to a procedure published in. ${ }^{9}$ Commercial hydroxylamine (Aldrich) was used as a 50\% aqueous solution.

\section{Reaction of 2-cyano-1-ethylthio-3-iminopyrrolizines 1a,b with hydroxylamine}

A suspension of 3-iminopyrrolizine $\mathbf{1 a}, \mathbf{b}(1 \mathrm{mmol})$ in $9 \mathrm{ml}$ of methanol was heated with aqueous hydroxylamine $(5 \mathrm{mmol})$ at $40-45^{\circ} \mathrm{C}$ for $30 \mathrm{~min}$. The solvent was partially removed under vacuum, water was added, and the precipitate formed was filtered off and washed with aqueous methanol. Recrystallization from aqueous acetone gave 1-hydroxylamino-3-iminopyrrolizines $\mathbf{2 a , b}$ in 92 and 99\% purity, respectively.

6-Ethyl-1-(hydroxyamino)-3-imino-5-propyl-3H-pyrrolizine-2-carbonitrile (2a). Yield 35\%, purity $92 \%$ (NMR data), mp 223-224 ${ }^{\circ} \mathrm{C} . v_{\max }(\mathrm{KBr}) \quad 3392,3071,2191,1656,1476 \mathrm{~cm}^{-1} ;{ }^{1} \mathrm{H}$ NMR (400.13 MHz): $\delta 11.00(1 \mathrm{H}$, br s, OH), $7.77(2 \mathrm{H}$, br s, NH), $6.45(1 \mathrm{H}, \mathrm{s}, \mathrm{H}-3), 2.75(2 \mathrm{H}$, m, $\mathrm{CH}_{2}-1$ of propyl), 2.34 (2H, q, ${ }^{3} J=7.6 \mathrm{~Hz}, \mathrm{CH}_{2}$ of ethyl), 1.47 (2H, m, $\mathrm{CH}_{2}-2$ of propyl), 1.08 $\left(3 \mathrm{H}, \mathrm{t},{ }^{3} J=7.6 \mathrm{~Hz}, \mathrm{CH}_{3}\right.$ of ethyl), $0.86\left(3 \mathrm{H}, \mathrm{t},{ }^{3} \mathrm{~J}=7.1 \mathrm{~Hz}, \mathrm{CH}_{3}\right.$ of propyl). ${ }^{13} \mathrm{C} \mathrm{NMR}(62.5$ MHz): $\delta 155.14$ (C-3), 143.57 (C-1), 130.08 (C-5), 127.45 (C-6), 123.86 (C-7), 115.64 (CN), 112.02 (C-8), 64.79 (C-2), 24.63 (C-1 of propyl), 22.55 (C-2 of propyl), 18.40 (C-1 of ethyl), 15.01 (C-2 of ethyl), 13.02 (C-3 of propyl). Anal. Calcd. for $\mathrm{C}_{13} \mathrm{H}_{16} \mathrm{~N}_{4} \mathrm{O}: \mathrm{C}, 63.93 ; \mathrm{H}, 6.56 ; \mathrm{N}$, 22.95. Found: C, 63.99; H, 6.59; N, 22.69.

1-(Hydroxyamino)-3-imino-5,6,7,8-tetrahydro-3H-pyrrolo[1,2-a]indole-2-carbonitrile (2b). Yield $41 \%$, mp $243-244^{\circ} \mathrm{C}$. $v_{\max }(\mathrm{KBr}) 3388,3192,2197,1662,1468 \mathrm{~cm}^{-1}$; ${ }^{1} \mathrm{H}$ NMR (400.13 $\mathrm{MHz}): \delta 10.97\left(1 \mathrm{H}\right.$, br s, OH), $7.77\left(2 \mathrm{H}\right.$, br s, NH), $6.34(1 \mathrm{H}, \mathrm{s}, \mathrm{H}-3), 2.75\left(2 \mathrm{H}, \mathrm{m}, \mathrm{CH}_{2}-5\right), 2.43$ $\left(2 \mathrm{H}, \mathrm{m}, \mathrm{CH}_{2}-8\right), 1.69$ (4H, m, $\left.\mathrm{CH}_{2}-6,7\right) .{ }^{13} \mathrm{C} \mathrm{NMR}(62.5 \mathrm{MHz}): \delta 154.73(\mathrm{C}-3), 144.10(\mathrm{C}-1)$, 126.23 (C-10), 125.19 (C-11), 123.69 (C-12), 115.89 (CN), 111.75 (C-9), 60.84 (C-2), 22.92 $\left(\mathrm{CH}_{2}-5\right), 22.32\left(\mathrm{CH}_{2}-7\right), 22.17\left(\mathrm{CH}_{2}-6\right), 21.88\left(\mathrm{CH}_{2}-8\right) .{ }^{15} \mathrm{~N}$ NMR $(25.36 \mathrm{MHz}): \delta-299(\mathrm{NH})$. Anal. Calcd. for $\mathrm{C}_{12} \mathrm{H}_{12} \mathrm{~N}_{4} \mathrm{O} \bullet\left(\mathrm{CH}_{3}\right)_{2} \mathrm{CO}$ : C, 62.94; H, 6.29; N, 19.58. Found: C, 62.78; H, 6.65; $\mathrm{N}, 19.76$. 


\section{Reaction of 2-carbamoyl-1-ethylthio-3-iminopyrrolizines 1c-e with hydroxylamine}

A. A suspension of 3-iminopyrrolizine 1c-e $(1 \mathrm{mmol})$ in $9 \mathrm{ml}$ of methanol was heated with aqueous solution of hydroxylamine $(5 \mathrm{mmol})$ at $40-45^{\circ} \mathrm{C}$ for $30 \mathrm{~min}$. The solvent was then removed under vacuum, the residue was analyzed (according to ${ }^{1} \mathrm{H} \mathrm{NMR}$, in all cases, the mixtures of 3-aminoisoxazoles 4c-e and 1-hydroxylamino-3-iminopyrrolizines 5c-e, $2.5: 1$, are formed) and then recrystallized from aqueous methanol to give either pure 3-aminoisoxazole (in the case of the pyrrolizine 1d) or a mixture of isoxazoles $\mathbf{4 c}, \mathbf{e}$ and 1-hydroxy-3-iminopyrrolizines 1c,e (in the case of the pyrrolizines 1c-e). After isolation of the isoxazole $4 \mathbf{d}$, the mixtures obtained and the mother liquor were separated by column chromatography $\left(\mathrm{Al}_{2} \mathrm{O}_{3}\right.$, methanol). 3Aminoisoxazoles 4c-e were isolated, while 1-hydroxylamino-3-iminopyrrolizines were lost during the workup.

B. A suspension of 3-iminopyrrolizine 1e $(1 \mathrm{mmol})$ in $9 \mathrm{ml}$ of $n$-propanol was heated with aqueous hydroxylamine $(5 \mathrm{mmol})$ at $85^{\circ} \mathrm{C}$ for $10 \mathrm{~min}$. After cooling of the reaction mixture to room temperature and partial removal of the solvent under vacuum, crystalline solid was formed. When washed with methanol, these crystals represent pure isoxazole $4 \mathrm{e}(40 \%)$.

3-Amino-5-(4-ethyl-5-propyl-1H-pyrrol-2-yl)isoxazole-4-carboxamide (4c). Yield 49\%, mp 207-208 ${ }^{\circ}$ C. $v_{\max }(\mathrm{KBr}) 3406,3352,3197,1676,1652,1569,1455 \mathrm{~cm}^{-1} ;{ }^{1} \mathrm{H}$ NMR (400 MHz): $\delta$ $11.93\left(1 \mathrm{H}\right.$, br s, NH), $7.35\left(2 \mathrm{H}\right.$, br s, $\left.\mathrm{CONH}_{2}\right), 6.63\left(1 \mathrm{H}, \mathrm{d},{ }^{4} J=2.3 \mathrm{~Hz}, \mathrm{H}-3\right), 5.62(2 \mathrm{H}$, br s , $\left.\mathrm{NH}_{2}\right), 2.52$ (2H, m, $\mathrm{CH}_{2}-1$ of propyl), $2.37\left(2 \mathrm{H}, \mathrm{q},{ }^{3} \mathrm{~J}=7.4 \mathrm{~Hz}, \mathrm{CH}_{2}\right.$ of ethyl), $1.56\left(2 \mathrm{H}, \mathrm{m}, \mathrm{CH}_{2}-\right.$ 2 of propyl), $1.10\left(3 \mathrm{H}, \mathrm{t},{ }^{3} \mathrm{~J}=7.4 \mathrm{~Hz}, \mathrm{CH}_{3}\right.$ of ethyl), $0.90\left(3 \mathrm{H}, \mathrm{t},{ }^{3} \mathrm{~J}=7.4 \mathrm{~Hz}, \mathrm{CH}_{3}\right.$ of propyl). ${ }^{13} \mathrm{C}$ NMR (62.5 MHz): $\delta 164.67$ (C-5 of isoxazole), $163.09\left(\mathrm{CONH}_{2}\right), 161.93$ (C-3 of isoxazole), 132.88 (C-5 of pyrrole), 123.36 (C-4 of pyrrole), 116.64 (C-2 of pyrrole), 111.57 (C-3 of pyrrole), 98.44 (C-4 of isoxazole), 27.16 (C-1 of propyl), 22.43 (C-2 of propyl), 18.30 (C-1 of ethyl), 15.60 (C-2 of ethyl), 13.69 (C-3 of propyl). ${ }^{15} \mathrm{~N}$ NMR (25.36 MHz): $\delta-226.96(\mathrm{NH}),-276$ $\left(\mathrm{CONH}_{2}\right)$, -340 $\left(\mathrm{NH}_{2}\right)$. Anal. Calcd. for $\mathrm{C}_{13} \mathrm{H}_{18} \mathrm{~N}_{4} \mathrm{O}_{2}$ : C, 59.54; H, 6.87; N, 21.37. Found: C, 59.29; H, 6.87; N, 21.56.

3-Amino-5-(5-butyl-4-propyl-1H-pyrrol-2-yl)isoxazole-4-carboxamide (4d). Yield 33\%, mp 213-214 ${ }^{\circ}$ C. $v_{\max }(\mathrm{KBr}) 3464,3375,3184,1635,1615 \mathrm{~cm}^{-1} ;{ }^{1} \mathrm{H}$ NMR $(400.13 \mathrm{MHz}): \delta 11.96(1 \mathrm{H}$, br s, NH), $7.41\left(2 \mathrm{H}\right.$, br s, $\left.\mathrm{CONH}_{2}\right), 6.60\left(1 \mathrm{H}, \mathrm{d},{ }^{4} J=1.8 \mathrm{~Hz}, \mathrm{H}-3\right), 5.61\left(2 \mathrm{H}\right.$, br s, $\left.\mathrm{NH}_{2}\right), 2.54$ $\left(2 \mathrm{H}, \mathrm{m}, \mathrm{CH}_{2}-1\right.$ of butyl $), 2.33\left(2 \mathrm{H}, \mathrm{m}, \mathrm{CH}_{2}-1\right.$ of propyl), $1.50\left(4 \mathrm{H}, \mathrm{m}, \mathrm{CH}_{2}-2\right.$, of butyl and propyl), $1.31\left(2 \mathrm{H}, \mathrm{m}, \mathrm{CH}_{2}-3\right.$ of butyl), $0.89\left(6 \mathrm{H}, \mathrm{m}, \mathrm{CH}_{3}\right.$ of butyl and propyl). ${ }^{13} \mathrm{C} \mathrm{NMR}(62.5$ MHz): $\delta 164.70\left(\mathrm{CONH}_{2}\right), 163.13$ (C-5 of isoxazole), 161.91 (C-3 of isoxazole), 133.45 (C-5 of pyrrole), 121.47 (C-4 of pyrrole), 116.66 (C-2 of pyrrole), 112.11 (C-3 of pyrrole), 98.45 (C-4 of isoxazole), 31.28 (C-2 of butyl), 27.23 (C-1 of propyl), 24.84 (C-1 of butyl), 23.86 (C-2 of propyl), 21.82 (C-3 of butyl), 13.77 (C-3 and C-4 of butyl and propyl). ${ }^{15} \mathrm{~N}$ NMR (25.36 MHz): $\delta$ -226 (NH), -273 $\left(\mathrm{CONH}_{2}\right),-339\left(\mathrm{NH}_{2}\right)$. Anal. Calcd. for $\mathrm{C}_{15} \mathrm{H}_{22} \mathrm{~N}_{4} \mathrm{O}_{2}: \mathrm{C}, 62.07 ; \mathrm{H}, 7.59 ; \mathrm{N}$, 19.31. Found: C, 61.99; H, 7.61; N, 19.26.

3-Amino-5-(4,5,6,7-tetrahydro-1H-indol-2-yl)isoxazole-4-carboxamide (4e). by the method B. Yield $40 \%, \mathrm{mp} 231-232^{\circ} \mathrm{C} . v_{\max }(\mathrm{KBr}) 3395,3241,1655,1515,1429 \mathrm{~cm}^{-1}$; ${ }^{1} \mathrm{H}$ NMR $(400.13$ MHz): $\delta 11.70\left(1 \mathrm{H}\right.$, br s, NH), $7.35\left(2 \mathrm{H}\right.$, br s, $\left.\mathrm{CONH}_{2}\right), 6.55(1 \mathrm{H}, \mathrm{s}, \mathrm{H}-3), 5.61\left(2 \mathrm{H}\right.$, br s, $\left.\mathrm{NH}_{2}\right)$, 
$2.58\left(2 \mathrm{H}, \mathrm{m}, \mathrm{CH}_{2}-7\right), 2.45\left(2 \mathrm{H}, \mathrm{m}, \mathrm{CH}_{2}-4\right), 1.71\left(4 \mathrm{H}, \mathrm{m}, \mathrm{CH}_{2}-5,6\right) .{ }^{13} \mathrm{C} \mathrm{NMR}(62.5 \mathrm{MHz}): \delta$ $164.51\left(\mathrm{CONH}_{2}\right), 162.95$ (C-5 of isoxazole), 162.10 (C-3 of isoxazole), 131.85 (C-5 of pyrrole), 118.17 (C-4 of pyrrole), 117.15 (C-2 of pyrrole), 110.79 (C-3 of pyrrole), 98.52 (C-4 of isoxazole), $23.20\left(\mathrm{CH}_{2}-7\right), 22.70\left(\mathrm{CH}_{2}-5\right), 22.49\left(\mathrm{CH}_{2}-6\right), 21.90\left(\mathrm{CH}_{2}-4\right) .{ }^{15} \mathrm{~N}$ NMR $(62.5 \mathrm{MHz})$ : $\delta-223(\mathrm{NH}),-332\left(\mathrm{NH}_{2}\right)$. Anal. Calcd. for $\mathrm{C}_{12} \mathrm{H}_{14} \mathrm{~N}_{4} \mathrm{O}_{2}$ : C, 58.54; H, 5.69; N, 22.76. Found: C, $58.17 ; \mathrm{H}, 5.82 ; \mathrm{N}, 22.63$.

6-Ethyl-1-(hydroxyamino)-3-imino-5-propyl-3H-pyrrolizine-2-carboxamide (5c). ${ }^{1} \mathrm{H}$ NMR $\left(400.13 \mathrm{MHz}, \mathrm{DMSO}-\mathrm{d}_{6}\right): \delta 10.90(1 \mathrm{H}$, br s, OH), $7.84(2 \mathrm{H}, \mathrm{br} \mathrm{s}, \mathrm{NHOH},=\mathrm{NH}), 6.80(2 \mathrm{H}$, br s, $\left.\mathrm{CONH}_{2}\right), 6.43(1 \mathrm{H}, \mathrm{s}, \mathrm{H}-3), 2.75\left(2 \mathrm{H}, \mathrm{m}, \mathrm{CH}_{2}-1\right.$ of propyl), 2.37 (2H, m, $\mathrm{CH}_{2}$ of ethyl), 1.55 ( $2 \mathrm{H}, \mathrm{m}, \mathrm{CH}_{2}-2$ of propyl), $1.09\left(3 \mathrm{H}, \mathrm{m}, \mathrm{CH}_{3}\right.$ of ethyl), $0.86\left(3 \mathrm{H}, \mathrm{m}, \mathrm{CH}_{3}\right.$ of propyl).

6-Butyl-1-(hydroxyamino)-3-imino-5-propyl-3H-pyrrolizine-2-carboxamide (5d). ${ }^{1} \mathrm{H}$ NMR (400.13 MHz): $\delta 10.90\left(1 \mathrm{H}\right.$, br s, OH), $7.84(2 \mathrm{H}$, br s, NHOH, $=\mathrm{NH}), 6.80\left(2 \mathrm{H}\right.$, br s, $\left.\mathrm{CONH}_{2}\right)$, $6.40(1 \mathrm{H}, \mathrm{s}, \mathrm{H}-3), 2.75\left(2 \mathrm{H}, \mathrm{m}, \mathrm{CH}_{2}-1\right.$ of butyl), $2.30\left(2 \mathrm{H}, \mathrm{m}, \mathrm{CH}_{2}-1\right.$ of propyl), $1.50(4 \mathrm{H}, \mathrm{m}$, $\mathrm{CH}_{2}-2$, of butyl and propyl), $1.31\left(2 \mathrm{H}, \mathrm{m}, \mathrm{CH}_{2}-3\right.$ of butyl), $0.89\left(6 \mathrm{H}, \mathrm{m}, \mathrm{CH}_{3}\right.$ of butyl and propyl).

1-(Hydroxyamino)-3-imino-5,6,7,8-tetrahydro-3H-pyrrolo[1,2-a]indole-2-carboxamide (5e). ${ }^{1} \mathrm{H}$ NMR (400.13 MHz): $\delta 10.88(1 \mathrm{H}$, br s, OH), $7.71(2 \mathrm{H}$, br s, NHOH, $=\mathrm{NH}), 6.77(2 \mathrm{H}$, br s, $\mathrm{CONH}_{2}$ ), 6.33 (1H, s, H-3), $2.75\left(2 \mathrm{H}, \mathrm{m}, \mathrm{CH}_{2}-5\right), 2.45$ (2H, m, $\left.\mathrm{CH}_{2}-8\right), 1.70$ (4H, m, $\left.\mathrm{CH}_{2}-6,7\right)$.

${ }^{13} \mathrm{C}$ NMR (62.5 MHz): $\delta 167.28$ (CONH2), 153.59 (C-3), 145.00 (C-1), 126.03 (C-10), 124.33, 124.30 (C-11, C-12), 111.90 (C-9), 83.67 (C-2), $22.92\left(\mathrm{CH}_{2}-5\right), 22.49\left(\mathrm{CH}_{2}-7\right), 22.40\left(\mathrm{CH}_{2}-6\right)$, $22.14\left(\mathrm{CH}_{2}-8\right)$.

\section{Acknowledgements}

Financial support from the Federation Agency on Science and Innovations of Russian Federation (Grant No. NSH-2241.2003.3) and the Russian Foundation for Basic Research (Grant No. 02-0333017 a) is gratefully acknowledged.

\section{References}

1. Ong, C. W.; Lai, M. C.; Jan, J. J.; Chang, Y. A. Heterocycles 2002, 57, 1303.

2. Zhang, S.; Zhao, X.; Kao, W.; Wang, J. U.S. Pat. US 566604, 1997; Chem. Abstr. 1997, 126, P305533m.

3. Sonnet, P.; Dallemagne, P.; Guillon, J.; Enguehard, C.; Stiebing, S.; Tanguy, J.; Bureau, R.; Rault S.; Auvray, P.; Moslemi, S.; Sourdaine, P.; Seralini, G.-E. Bioorg. Med. Chem. 2000, $8,945$.

4. Anderson, W. K.; Mach, R. H. J. Heterocycl. Chem. 1990, 27, 1025.

5. Csuzdi, E.; Pallagi, I.; Jerkovich, G.; Solyom, S. Synlett 1994, 429. 
6. Mataka, S.; Kitagawa, H.; Tsukinoki, T.; Tashiro, M.; Takahashi, K.; Kamata, K. Bull. Chem. Soc. Jpn. 1995, 68, 1969.

7. Dalla Croce, P.; La Rosa, C. Heterocycles 2001, 55, 1843.

8. Flamini, A.; Fares, V.; Capobianchi, A.; Valentini, V. J. Chem. Soc., Perkin Trans. 1 2001, 3069.

9. Sobenina, L. N.; Mikhaleva, A. I.; Trofimov, B. A. Khim. Geterotsikl. Soed. 1995, 418.

10. Sobenina, L. N.; Mikhaleva, A. I.; Toryashinova, D.-S. D.; Trofimov, B. A. Sulfur Lett. 1996, 20, 9.

11. Sobenina, L. N.; Mikhaleva, A. I.; Toryashinova, D.-S. D.; Kozyreva, O. B.; Trofimov, B. A. Sulfur Lett. 1997, 20, 205.

12. Sobenina, L. N.; Mikhaleva, A. I.; Petrova, O. V.; Toryashinova, D.-S.D; Kozyreva, O. B.; Larina, L. I.; Il'ícheva, L. N.; Trofimov, B. A. Zh. Org. Khim. 1999, 35, 1241.

13. Garrone, A.; Fruttero, R.; Tironi C.; Caseo, A.; J. Chem. Soc., Perkin Trans. 2 1989, 1941.

14. Sobenina, L.N.; Drichkov, V.N.; Mikhaleva, A. I.; Petrova, O. V.; Ushakov, I. A.; Trofimov, B. A. Tetrahedron 2005, submitted.

15. Bodenhausen, G.; Ruben, D. J. Chem. Phys. Lett. 1980, 69, 185.

16. Bax, A; Summers, M. F. J. Am. Chem. Soc. 1986, 108, 2093. 